\title{
Improved Eco-Friendliness of a Common Flame Retardant through Inclusion Complexation with Cyclodextrins
}

Nanshan Zhang, Erol Yildirim", Cody P. Zane, Jialong Shen, Nelson Vinueza, David Hinks, Alan E. Tonelli*, and Melissa A. Pasquinelli*

Fiber and Polymer Science Program, North Carolina State University, Campus Box 8301, Raleigh, NC 27695-8301, USA
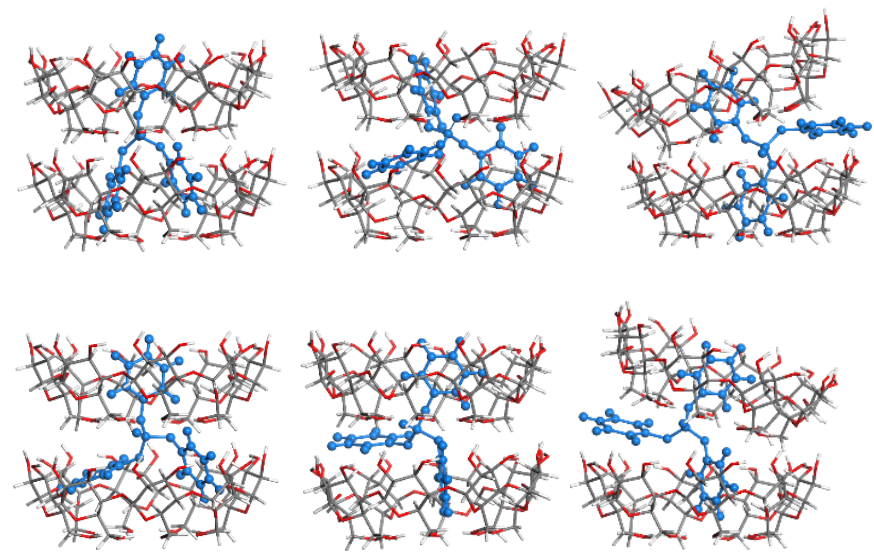

Figure S1. Six different initial structures constructed

for 1:2 models of TPP: $\gamma$-CD ICs in the head-to-tail (HT) configuration. 


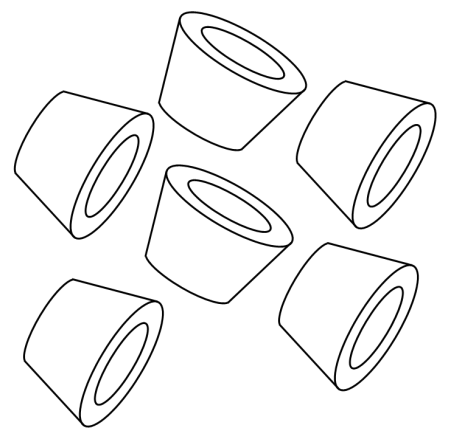

(a)
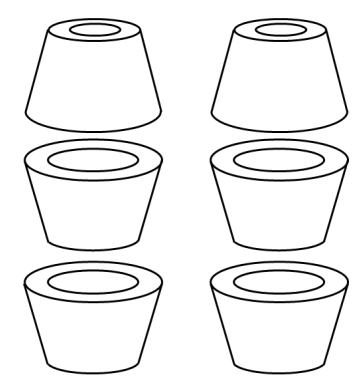

(b)

Figure S2. Types of crystal structures that CDs commonly form: (a) cage herringbone crystal, and (b) head-to-head; tail-to-head; tail-to-tail columnar-type (3- $\gamma$-CD repeating unit).

Table S1. Energies calculated from the PM6 calculations for the structures given in Figure 2. Graphs of these values are also given in Figure 3.

\begin{tabular}{|c|c|c|c|c|c|c|}
\hline & & $\begin{array}{l}\Delta \mathrm{H}_{\mathrm{f}} \\
(\mathrm{kcal} / \mathrm{mol})\end{array}$ & $\begin{array}{l}E_{\text {inter }} \\
(\mathrm{kcal} / \mathrm{mol})\end{array}$ & $\begin{array}{l}E_{\text {complex }} \\
(\mathrm{kcal} / \mathrm{mol})\end{array}$ & $\begin{array}{l}\mathrm{E}_{\mathrm{conf}}(\mathrm{CD}) \\
(\mathrm{kcal} / \mathrm{mol})\end{array}$ & $\begin{array}{l}\mathrm{E}_{\text {conf }}(\mathrm{TPP}) \\
(\mathrm{kcal} / \mathrm{mol})\end{array}$ \\
\hline \multirow[t]{3}{*}{$\alpha$} & TT & -2871.15 & -267.98 & -148.52 & 42.64 & 7.97 \\
\hline & HT & -2900.18 & -278.96 & -177.55 & 28.29 & 5.54 \\
\hline & $\mathrm{HH}$ & -2913.23 & -270.71 & -190.60 & 20.47 & 2.04 \\
\hline \multirow[t]{3}{*}{$\beta$} & TT & -3362.79 & -327.01 & -196.85 & 25.64 & 7.56 \\
\hline & HT & -3384.92 & -339.05 & -218.98 & 19.27 & 5.74 \\
\hline & $\mathrm{HH}$ & -3407.12 & -333.82 & -241.18 & 11.31 & 3.38 \\
\hline \multirow[t]{3}{*}{$\gamma$} & TT & -3778.41 & -401.53 & -242.40 & 29.54 & 6.85 \\
\hline & HT & -3808.82 & -412.84 & -272.81 & 24.11 & 3.44 \\
\hline & $\mathrm{HH}$ & -3816.80 & -405.21 & -280.79 & 20.57 & 1.16 \\
\hline
\end{tabular}




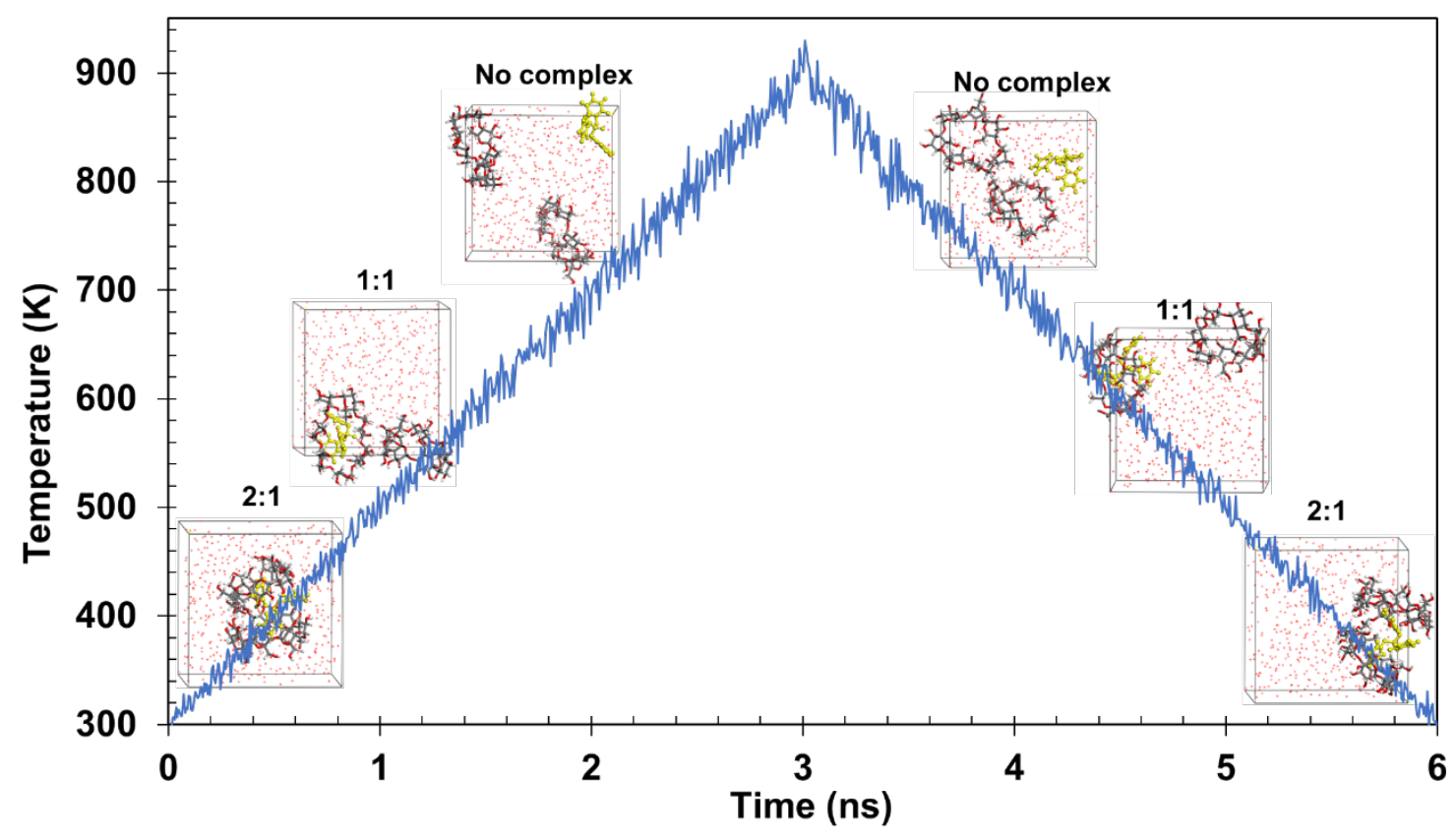

Figure S3. Snapshots along an MD simulation trajectory of 1:2 TPP: $\beta$-CD IC complexes in water being heated and then cooled. 